\title{
Antimykotische Therapie bessert atopisches Ekzem
}

\section{Eine IgE-vermittelte Sensibilisierung gegenüber Hefen wird häufig bei Patienten mit atopischem Ekzem beobachtet, vor allem wenn sich die Ekzemherde am Kopf sowie im Hals- und Schulterbereich befinden. In einer randomisierten, doppelblinden, kontrollierten Studie überprüfte eine finnische Arbeitsgruppe die Wirksamkeit einer systemischen Behandlung mit Ketoconazol unter Berück- sichtigung des Hefewachstums auf der Haut.}

nsgesamt 80 Patienten mit atopi-
schem Ekzem und einer Sensibilisie-
rung gegenüber P. ovale oder C. albicans
im Hauttest erhielten über 30 Tage oral
entweder täglich Plazebo oder 200 mg
Ketoconazol. Rückfettende Externa
oder Zubeitungen mit $1 \%$ Hydrocorti-
son waren während dieser Zeit zusätz-
lich erlaubt, danach war auch die An-
wendung stärker wirksamer Kortiko-
steroide bei Bedarf zulässig. Zu Thera-
piebeginn, nach einem und nach drei
Monaten wurden das Hefewachstum
auf der Haut und im Rachen, das spezi-
fische Serum-IgE gegen P. ovale, C. albi-
cans und S. cerevisiae, das Serum-Ge-
samt-IgE und die Schwere des Ekzems
erfasst.

Gegenüber der Plazebo-Gruppe kam es bei den mit Ketoconazol behandelten Patienten nach einem Monat Therapie zu einer hochsignifikanten Besserung: Es zeigten sich eine Verminderung des Juckreizes und ein Rückgang der Hautveränderungen - weniger Exkoriationen, Lichenifikationen, Erytheme, Papeln - und eine verminderte Hauttrockenheit. Dagegen kam es bei den Patienten unter Plazebo nur zu einer deutlichen Zunahme der ekzemfreien Hautbereiche. In der KetoconazolGruppe reduzierten sich die für P. ovale positiven Kulturen von $60 \%$ auf $31 \%$, in der Plazebo-Gruppe gingen sie nur von $64 \%$ auf $56 \%$ zurück. Besonders gut sprachen Patientinnen mit kulturellem Nachweis von Hefen auf die Ketoconazol-Behandlung an.

Die Autoren der Studie kommen zu dem Schluss, dass saprophytäre Hefen eine Allergenquelle für Patienten mit atopischem Ekzem darstellen könnten, welche zu einer Verschlechterung des Hautbefundes führt. Deshalb sollten diejenigen, bei denen in Kultur Hefen nachgewiesen wurden und die spezifische Serum-IgE-Antikörper aufweisen, systemisch antimykotisch behandelt werden.

\section{Fazit}

Die Rolle von Staphylokokken-Antigenen als Triggerfaktoren des atopischen Ekzems ist bekannt. Therapeutische Konsequenz ist eine antibiotische Behandlung, die in der Regel zu einer raschen Besserung des Ekzems führt. Eine ähnliche Rolle können offensichtlich
D ie Untersuchung „Prevention and Incidence of Asthma and Mite Allergy" (PIAMA), die derzeit an verschiedenen Zentren in den Niederlanden läuft, soll herausfinden, ob milbendichte Matratzenbezüge die Sensibilisierung von Kindern verhindern können, die ein familiär erhöhtes Allergierisiko haben. Die Kinder werden seit ihrer Geburt (Juli '96 bis Oktober '97) regelmäßig untersucht. Zusätzlich zum Interventionsast gibt es eine Vergleichsgruppe von nicht familiär belasteten Kindern. Daraus erhoffen sich die Initiatoren von PIAMA Erkenntnisse zum Ausmaß des Erkrankungsrisikos von Kindern aus Allergikerfamilien. Der Wert der Studie in diesem Punkt dürfte jedoch begrenzt sein, da die Vorausset-

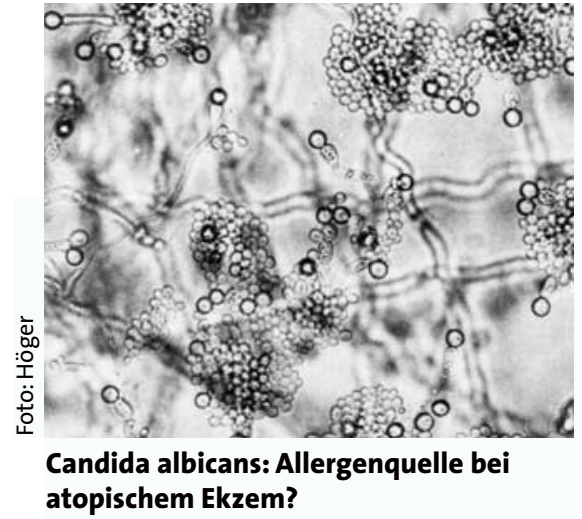

Hefen spielen. Weitere Arbeiten sind nötig, um diesen Sachverhalt zu klären. Zunächst sollte, wie von den Autoren empfohlen, nur bei Nachweis von Hefen in Kultur und Sensibilisierung antimykotisch behandelt werden. $\mathrm{Ob}$ dabei unter Berücksichtigung des Nebenwirkungsrisikos Ketoconazol die erste Wahl ist, muss untersucht werden.

A. Niedermeier, München

P. Lintu et al. Systemic ketoconazole is an effective treatment of atopic dermatitis with IgE-mediated hypersensitivity to yeasts. Allergy 2001; 56: 512-7

\section{Allergenvermeidung als Lifestyle}

\section{Allergiker sind hoch motiviert, allergenvermeidende Maßnahmen durchzuführen - was eine Studie zum natürlichen Verlauf von Aller- gien vor nicht geringe Schwierigkeiten stellt.}

zung gleicher "Umweltbedingungen“ in den beiden Gruppen offenbar nicht besteht.

Die erste Auswertung der Daten zeigt klar, dass sich der Lebensstil von Familien mit oder ohne Allergie deutlich unterscheidet. Viele Allergiker-Eltern bemühen sich intensiv um allergenvermeidende Maßnahmen. Dies gilt insbesondere, wenn beide Elternteile allergisch sind. In einer Befragung gaben 53,3\% dieser Eltern an, bei der Einrichtung der Wohnung auf allergenvermeidende Maßnahmen zu achten. Nicht-Allergiker-Paare taten dies nur zu 3,9\%. Kinder von Allergikern wachsen auch signifikant häufiger in einer Umgebung auf, die frei von Katzen und Tabakrauch ist. Die Kinderzimmer werden häufiger mit glatten 